\title{
REPRESENTAÇÕES SOBRE CORPO E EDUCAÇÃO DA MULHER NA EXPANSÃO DO ESCOTISMO E DO BANDEIRANTISMO DURANTE NAS PRIMEIRAS DÉCADAS DO SÉCULO XX'
}

\author{
DR. CARLOS HEROLD JR. \\ Departamento de Educação Física, Centro de Ciências da Saúde, \\ Universidade Estadual de Maringá; Programa de Pós-graduação em Educação, \\ Setor de Educação, Universidade Federal do Paraná; Programa de Pós-graduação \\ em Educação, Setor de Ciências Humanas, Letras e Artes, Universidade \\ Estadual do Centro-Oeste (Maringá - Paraná - Brasil) \\ E-mail: carlosherold@hotmail.com
}

\section{DR. ALEXANDRE FERNANDEZ VAZ}

Departamento de Metodologia de Ensino e Programas de Pós-graduação em Educação e Interdisciplinar em Ciências Humanas, Centro de Ciências da Educação,Universidade Federal de Santa Catarina; Pesquisador CNPq (Florianópolis - Santa Catarina - Brasil)

E-mail: alexfvaz@uol.com.br

\begin{abstract}
RESUMO
O objetivo deste trabalho é analisar representações sobre corpo e educação feminina no interior da expansão do movimento escoteiro, que ocorreu nas primeiras décadas do século XX. Estudamos trabalhos de especialistas em história da educação, escritos de fundadores do movimento na Inglaterra e Estados Unidos e de artigos sobre o Bandeirantismo brasileiro. Concluímos que as atividades corporais e a educação do corpo praticadas no escotismo e no Bandeirantismo foram espaços de tensão entre a manutenção e a mudança dos papéis sociais atribuídos às meninas e aos meninos.
\end{abstract}

PALAVRAS-CHAVE: Corpo; escotismo; bandeirantismo; História da Educação.

I. O trabalho é resultado parcial do projeto Corpo e educação na América do Sul: uma análise comparada da expansão escoteira no Brasil, Argentina e Uruguai ( 1910 - 1946) e do programa de pesquisas Teoria Crítica, Racionalidades e Educação (III), ambos financiados pelo CNPq. Além desses auxílios à pesquisa, os estudos contaram o recebimento de uma bolsa Pós-doc Reuni-UFSC. 
O escotismo foi criado em 1907 para reunir meninos e rapazes visando à "construção do caráter" (ROSENTHAL, 1986). Nos anos que seguiram, meninas começaram, informalmente, a organizar seus grupos. Diante do crescimento da participação das garotas, em 1910 foi criado o Guiding, ${ }^{2}$ ramo feminino do Scouting. Lugares sociais de homens e mulheres, a educação e a educação do corpo passaram a ser assuntos presentes no interior do movimento. Eles são o tema deste trabalho.

Esses debates tocam em questões com relevantes implicações para quem se dedica à história da educação corporal, da educação feminina e da expansão do escotismo. Ao estudá-los, pretendemos entender como aqueles que pensaram o escotismo e o Bandeirantismo conceberam a educação corporal para a formatação e "reformatação" dos gêneros (PROCTOR, 2009) nas primeiras décadas do século XX.

Optamos por operar, com alguma liberdade, com o conceito de representação, tal como formulado por Chartier (2002). ${ }^{3}$ Procuramos apreender representações sobre corpo, educação, meninas e meninos, existentes durante a divulgação do escotismo e do Bandeirantismo, buscando captar suas tensões no contexto em que foram desenvolvidas. Essa escolha é importante para pensarmos relacionamentos (de aproximação e/ou distanciamento) entre as representações relativas à formação do "menino" e da "menina" no escotismo e no Bandeirantismo, conduzidos a partir da importância do corpo em seu interior.

The two movements cannot be studied separately because the social categories of "boyhood" and "girlhood" are always constructed in relation to each other. By exploring the interaction between the girls and boys, it is possible to study how there two movements reinforced each other dialectically (PROCTOR, 2002, p. 12).

A importância dessa opção analítica já havia sido sinalizada por Scharadgrodsky (2008). Ao centrar sua atenção no desenvolvimento do escotismo argentino, ele optou por analisar o impacto do movimento na configuração "de una cierta masculinidad", reconhecendo, todavia, que as inquietações dos proponentes do movimento scout também estavam "dirigidas a las mujeres" (SCHARADGRODSKY, 2008, p. I 56).

2. A decisão de Baden-Powell em criar as Girl Guides ocorreu depois de um grupo de garotas solicitar sua participação em um encontro escoteiro que ocorreu em Londres no ano de 1909. No Brasil, o ramo feminino ficou conhecido como Bandeirantismo, tendo início em 13 de Agosto de 1919, no Rio de Janeiro. Para apontamentos históricos relativos ao desenvolvimento do Bandeirantismo no Brasil, ver Blower (1994), sobretudo, da página 93 al 02.

3. Ao utilizarmos esse apontamento metodológico de Chartier (2002), consideramos a possibilidade de "pensar-se uma história cultural do social que tome por objecto a compreensão das formas e dos motivos - ou, por outras palavras, das representações do mundo social - que, à revelia dos actores sociais, traduzem as suas posições e interesses objectivamente confrontados e que, paralelamente, descrevem a sociedade tal como pensam que ela é, ou como gostaria que fosse" (CHARTIER, 2002, p. 19). 
Esta indicação leva-nos a formular a hipótese segundo a qual a educação corporal é um tema capital tanto nas pressões sofridas pelo escotismo para franquear a presença de garotas nas atividades corporais escoteiras (em um claro sinal de que a divisão de papéis sociais e formativos entre meninos e meninas sofria tensões no início do século $X X)$, quanto no esforço dos idealizadores do movimento em sublinharem essa divisão, direcionando essas mesmas pressões para perfis formativos da mulher relacionados aos tradicionais papéis de filha, irmã, esposa e mãe... todas belas, maternais e femininas, se podemos parafrasear o título do livro de Goellner (2003).

O trabalho está dividido em três partes. Na primeira, explicitamos as problemáticas geradas pela participação de meninas nas atividades escoteiras, apoiando-nos em historiografia da educação escoteira. Depois observamos como essa participação foi defendida por duas figuras centrais no escotismo das primeiras décadas do século $X X$, a partir de livros que escreveram: Robert Baden-Powell ( 857 - 194 I), fundador do movimento, Juliette Gordon Low ( 1860 - 1927), divulgadora do escotismo nos Estados Unidos da América e defensora do feminino em seu interior. Por fim, abordamos a presença de meninas no escotismo brasileiro, analisando artigos de periódicos educacionais e escoteiros circulantes no início do século passado.

\section{PARADOXO NA EDUCAÇÃO CORPORAL: MENINAS EM UM "MOVIMENTO" DE MENINOS.}

A incorporação de garotas às atividades escoteiras gerou grande discussão na sociedade inglesa na primeira década do século $X X$, quando a participação feminina era vista como polêmica (PROCTOR, 2009). Afinal, a presença feminina poderia gerar uma opinião pública que relacionasse o escotismo aos interesses femininos. Além disso, havia a avaliação de que as atividades escoteiras seriam inadequadas às meninas, masculinizando-as por meio do etos militar presente no movimento. Tão importante quanto essas ponderações, era a crença de que a presença delas afeminaria os garotos, potencializando o medo relativo à perda de virilidade, um dos principais motes que sustentaram a criação do escotismo (ROSENTHAL, 1986; MACLEOD, 1983; JEAL, 200I).

Outros problemas foram levantados e inquietavam os dirigentes do movimento. Por um lado, as mulheres seriam exageradamente civilizadas - um problema para um movimento que criticava o "excesso de civilização" que teria "amolecido os homens" (JEAL, 200I) -, mas, por outro, muito primitivas. A herança cristã via na mulher ou a origem do pecado ou a incapacidade de deliberar sobre suas próprias vontades, temor que proporcionou o escopo de ação para o movimento escoteiro junto às meninas (PROCTOR, 2009). 
Essa visão estava presente nas justificativas do conjunto de atividades a serem praticadas, que incluía "fitness training, handicraft, first-aid, homemaking skills, hiking, and camping" (PROCTOR, 2009, p. 14). Com a perspectiva de que "os ingleses" estavam se tornando efeminados e sem energia no início do século $X X$ - época sabidamente de forte tensão nacionalista com corolários bélicos -, a possibilidade de atividades que colocassem meninos e meninas juntos não era vista com simpatia por muitos. Elas resultariam na diminuição do interesse pelas atividades escoteiras por parte dos meninos e, também, no comprometimento do esprit de corps proporcionado pela vivência dos jovens em uma comunidade eminentemente masculina, sendo a experiência dessa comunhão um dos traços emblemáticos do sucesso do escotismo junto a meninos e rapazes do mundo inteiro (PROCTOR, 2009).

Tornando esses temores ainda mais agudos, os acontecimentos da Primeira Grande Guerra e a concomitante presença de mulheres na substituição de homens que estavam em campos de batalha, ou no socorro aos feridos (PROCTOR, 2009), fizeram mais evidentes as inseguranças quanto à escalada de poder feminino. ${ }^{4}$ Isso foi percebido dentro do movimento escoteiro, em que, diz Macleod ( 1983, p. I 83), temia-se que o ramo feminino superasse o masculino. Com efeito, na metade da década de 1920 contava-se 500.000 Girl Guides, 200.000 mil a mais que o número de Boy Scouts na Inglaterra (JEAL, 200 I, p. 479).

Apesar desses "medos", as atividades que aconteciam nos grupos continuaram a agregar um grande número de meninas! A vida ao ar livre, os acampamentos, as trilhas, o espírito aventureiro, tornaram-se um grande atrativo, principalmente, se for considerada a insatisfação feminina nas camadas médias com as "societal expectations for females" (PROCTOR, 2009, p. 6). No início do século XX, as atividades oferecidas pelo escotismo e ambicionadas pelas meninas eram vistas como uma "benção" (JEAL, 200 I, p. 479) para uma geração de mulheres infelizes com o casamento, não casadas ou que passaram a valorizar mais a amizade com outras mulheres, em detrimento do casamento ou da maternidade. Interessavam as emoções proporcionadas pelas atividades nas florestas, o aprendizado de pequenas técnicas usadas em campos de batalha (código Morse, por exemplo), a experimentação do clima de aventura e utilidade compartilhada com as companheiras. Essa maior possibilidade de liberdade era um intenso desejo das garotas, afinal, se os

4. Caire (2002, p. 55) mostra que a Primeira Guerra Mundial foi um conflito que contou com grande participação das mulheres também nos campos de batalha: "Uma mudança profunda de atitude em relação à mulher ocorreu a partir do primeiro conflito mundial. Como a guerra se tornou total e mecanizada e as necessidades de mão-deobra se multiplicaram para sustentar o esforço de guerra na retaguarda, foram convocadas todas as forças da nação. Houve mobilização ou requisição de mulheres, inclusive voluntárias, para servirem e até mesmo desempenharem missões como combatentes na Rússia e nos países da Europa Oriental." 
meninos eram estimulados a lutar por sua independência moral e financeira, "girls seemed condemned to a perpetual state of childhood and dependence in Victorian and Edwardian Britain." (PROCTOR, 2002, p. 20). Por essa razão, "Girls, who were controlled and monitored more than boys of the same age, craved the freedom that boys enjoyed." (PROCTOR, 2002, p. 20).

Baden-Powell resistiu à ideia de permitir que garotas praticassem as atividades inventadas, especificamente, para os meninos. Isso pode ser observado, diz Jeal (200 I ), no fato de que a inserção de meninas dar-se-ia por meio de outra estrutura organizacional que não a já montada para o escotismo. Soma-se a isso o fato de que a adoção de um nome que não fosse a "palavra sagrada Scout" (JEAL, 200 I , p. 469) era imperativa. Ante a incontornável presença feminina, adequou-se a organização do movimento com o fim de evitar os já mencionados temores, incorporando-se a participação das meninas. Ao final da primeira guerra, a organização do Guiding já possuía uma dimensão relevante dentro do conjunto do escotismo (PROCTOR, 2009). Essa situação possibilitou que se coadunassem os dois pontos fundamentais para o sucesso do movimento: a) o prazer proporcionado pelas atividades de aventura ao ar livre, com o b) apoio de vários setores sociais e instituições a uma formação que direcionava as meninas aos afazeres e habilidades necessárias para o cuidado da casa e dos filhos.

Proctor (2002) analisa as dificuldades de Baden-Powell com o súbito interesse das meninas pelas atividades. Na história do desenvolvimento do ramo feminino é notório o que a mesma autora chamou de "participação clandestina" das meninas nas atividades escoteiras. ${ }^{5}$ A separação do movimento em dois ramos foi uma alternativa para ultrapassar esses obstáculos, oferecendo-se práticas imbuídas de patriotismo para ambos os sexos, mas que considerassem as particularidades formativas atinentes aos lugares sociais determinados para cada um. A força e a longevidade dessas propostas se apoiaram na capacidade de "addressing a more general concern in early twentieth-century Britain with racial purity, degeneration, and appropriate sexuality" (PROCTOR, 2002, p. I I - I2). As justificativas para lidar com o tal "paradoxo" eram criativas:

\footnotetext{
Guides were taught to be sympathetic and trained in home skills, and also they were taught to desire the company of men. Leaders thought girls should become wives, not independent women. Some wanted to train girls to be "companions" for men, but no equals; they wanted to save girls from depravity and moral disintegration, so that as woman, in turn, could save men (PROCTOR, 2002, p. 25).
}

5. Foi essa participação que "convenceu" Baden-Powell a ceder às pressões femininas formalizadas no encontro de 1909. Ver nota I. 
Ao conviver com essa dificuldade organizacional e ideológica relacionada aos papéis assumidos por meninos e meninos, o Bandeirantismo proporcionou as condições para que o movimento atingisse uma variada gama de interesses sociais, políticos e de classe. A participação das mulheres nos movimentos de juventude aconteceu em vários países com características sociais e orientações políticas muito diferentes entre si. Na Itália e na Alemanha, por exemplo, esses movimentos eram fortemente nacionalistas, "shaping youth was a governmental project, and in each case, girls ' physical fitness and outdoor activities were aimed to build strong mothers for the nation." (PROCTOR, 2009, p. 69).

\section{DA RESISTÊNCIA À "INCORPORAÇÃO” FEMININA: ATIVIDADES SCOUTS E EDUCAÇÃO GUIDES}

O processo de reestruturação do escotismo para a incorporação de meninas estava manifesto no pensamento de seus idealizadores. Baden-Powell ( 1908, p. 13), antes mesmo de testemunhar o interesse das garotas no escotismo, já entendia que as mulheres poderiam exercer papéis sociais para além dos de mãe e esposa: "[...] girls as well as boys may well learn scouting while they are young, and so be able to do useful work in the world as they grow older." Vale notar que esse "passo além" da maternidade e do casamento foi visto como possível se fosse dado em uma direção profissional tradicionalmente ocupado por mulheres: a enfermagem. Florence Nightingale ${ }^{6}$ personificaria um exemplo do que poderiam fazer mulheres que fossem "corretamente" educadas (BADEN-POWELL, 1908). Julliete Low também avaliava a enfermagem como importante. Primeiro por ser uma carreira profissional (LOW; BADEN-POWELL; BADEN-POWELL, 1917, p. 16), algo com o que as mulheres poderiam se preocupar em "tempos incertos", mas também por ser ela "facilmente aprendida" por mulheres, de forma que "every woman is a better wife and mother for having been a nurse first." (LOW; BADEN-POWELL; BADEN-POWELL, 1917, p. 17).

Low, baden-powell e baden-powell (1917) observava que as mulheres exerciam uma grande influência sobre os homens, que superava aquela que aqueles tinham entre si. ${ }^{7}$ Por isso, defendia a necessidade de um "fortalecimento do caráter" feminino para que tivesse condição de apoiar os homens e os meninos, quando eles precisassem (LOW, BADEN-POWELL; BADEN-POWELL, I97।, p. 13). Isso não

6. Enfermeira que teve atuação marcante no cuidado de soldados ingleses feridos em guerras.

7. Sintomático dessa influência e da preocupação que ela gerava, é o fato de Baden-Powell (1922), ao diagnosticar as dificuldades que levavam o homem à degeneração, fazer uma reveladora lista de coisas a serem "contornadas": bebida, cigarro, masturbação, assistir sports...e mulheres! 
deveria levar à crença de que se quisera sublinhar uma superioridade da mulher em relação ao homem. O contrário seria o correto: tratava-se de se desenvolver humildade e atenção para as demandas masculinas. A não observância dessas necessidades era vista como uma das causas das misérias e desastres no mundo de então: através desse prisma, os problemas sociais aconteciam porque as mulheres não sabiam mais o seu "lugar correto" (LOW;BADEN-POWELL; BADEN-POWELL 19|7, p. I3) ou não aplicariam legitimamente suas forças, tal como fizera, por exemplo, Nightingale.

Por tudo isso, a educação feminina se tornou uma questão urgente para os proponentes do escotismo. Baden-Powell (1933) também se alinhava às críticas que viam na educação feminina uma subestimação da capacidade das mulheres. Em alguns momentos ele percebera que os meninos e as meninas tinham gostos semeIhantes no que diz respeito às atividades que desenvolviam, tornando o escotismo possível de ser praticado também pelas moças. Mesmo que possamos observar em Baden-Powell a atenção sobre o valor da educação das mulheres de uma forma que atendesse às necessidades específicas dos "novos tempos", há nela a permanência de atribuições sociais presentes em outras épocas. Se de um lado Baden-Powell defende um "passo além" dos antigos lugares da mulher na sociedade, em questões pequenas transparecem representações sobre a feminilidade que relacionava as meninas à futilidade. Ao falar do uniforme, por exemplo, Baden-Powell pondera que, além da possibilidade de ele "esconder" ou "fazer esquecer" as desigualdades sociais, importante era considerar o do "apelo estético" que ele tinha para as garotas ${ }^{8}$ (BADEN-POWELL, 1933, p. 304).

Baden-Powell (1933, P. I3) avaliava haver objetivos educacionais igualmente importantes para meninos e meninas: a finalidade do escotismo e do Bandeirantismo era formar "cidadãos" plenos de três pontos: saúde, felicidade e solicitude. Todavia, reconhecia as "particularidades" da formação a ser proposta às moças:

[...] we shall have a considerable leaven in the population of women trained in thrift, housekeeping, mother-craft, as well as in character and efficiency for work in the world, and in friendship with their sisters in other countries. (BADEN-POWELL, 1933, p. 305).

A modéstia era um sentimento que complementaria a "mulher de corpo forte". Para Low, Baden-Powell e Baden-Powell (1917, p. 15) as Bandeirantes seriam reconhecidas pelo seu comportamento circunspecto, por não propagandearem suas virtudes e, sobretudo, por "never draw attention to themselves unnecessarily by behaving noisily and talking or laughing loudly in public." Ela advertia que isso

8. Para os meninos o uniforme tinha outros "apelos", avaliados como mais legítimos e ligados ao culto do soldado pelo seu equipamento e batalhão. 
deveria ocorrer de modo ainda mais premente na presença de homens ou meninos, principalmente (mas não só), em ocasiões sociais. Para tais momentos as recomendações eram mais precisas: "girls should not risk, by their manner of dress or method of dancing, bringing temptation to others." (LOW; BADEN-POWELL; BADEN-POWELL, 1917, p. 15).

Low constatava a necessidade, e mesmo sua realização, de as meninas se movimentarem e participarem de jogos, o que as fazia "mais fortes e mais atléticas". Como resultado, "mais saúde e mais beleza". Essa participação estimularia o surgimento de uma geração de "out-of-doors girl(s)" (LOW, BADEN-POWELL; BADEN-POWELL, 1917, p. 45). Uma mulher com corpo forte era fundamental: "A girl who develops a strong agile body, at the same time improves her brain. A girl with weak, flabby muscles cannot have the strength of character that goes with normal physical power." (LOW; BADEN-POWELL; BADEN-POWELL, 1917, p. 14).

As atividades ideais para as garotas seriam aquelas que não fossem violentas, mas demandantes de pouca força física. Low, Baden-Powell e Baden-Powell (1917, p. 45) advogava que as de "esforço continuado" (natação ou caminhadas, sugere ela) seriam ideias. Mesmo assim, não deixava de afirmar o trabalho sobre a maleabilidade do corpo frente às exigências a ele postas: "In fact, each one of us can mold her own body, very much as a sculptor fashions a statue." (LOW; BADEN-POWELL; BADEN-POWELL, 1917, p. 77). O corpo no escotismo deveria ser educado visando à saúde individual da mulher e o bem-estar das "futuras gerações":

It is the duty of each one of us, both for our own sake, and for the benefit of future generations, to perfect our own sakes, and for the benefit of future generations, to perfect our physical frame. It is a duty to be strong and beautiful in body as well as in mind and spirit. (LOW; BADEN-POWELL; BADEN-POWELL, 1917, p. 77).

Em que pese o reconhecimento de que as mulheres estavam mais "atléticas", para Low; Baden-Powell; Baden-Powell (1917, p. 83) seguia sendo o lar seu melhor destino: seria essa a utilidade da "boa formação" em jogo. Isso era afirmado com a certeza de quem via o âmbito privado como o adequado às mulheres, colocando-o como fim para todas as ambições formativas pautadas na educação corporal das Girl Guides. Atividades corporais antes vistas como inadequadas às meninas passaram a ser importantes no fomento das condições físicas, morais e intelectuais necessárias às futuras esposas e mães "da nação".

\section{A FORÇA E A FRAQUEZA DO CORPO FEMININO: EDUCAÇÃO BANDEIRANTE NO BRASIL}

No Brasil essas representações também tiveram importância, mobilizando políticos, professores e todos aqueles que pensavam o novo lugar da mulher. A Primeira 
Guerra Mundial fez a relação homens e mulheres ser repensada. Convidada para falar às Bandeirantes, Maira Sophia Bulcão Vianna sublinhou o valor que as mulheres tiveram no conflito: "Arrancadas ao ambiente familiar, pelas duras contingencias da vida, em nada se mostram inferiores ao homem, treinado, durante séculos, para esses duros misteres." (VIANNA, 1937a, p. 191). A Federação das Bandeirantes do Brasil ( 1947) também buscou o endosso de seu "método", utilizando participação das Girls Guides nas lidas da guerra.

Bandeirantismo foi tido como um sinalizador da força das mulheres em todo mundo, não tendo sido diferente no Brasil. A questão era dirigir essa força para fins socialmente úteis e adequados para se contornar "a crise". Roquette Pinto ( 195 I) constatava uma crise de valores na sociedade brasileira, criticando a formação das jovens. Denunciava que elas cresciam expostas a uma cultura marcada por "letra de sambas de carnaval com amores desfeitos copiosamente chorados" (ROQUETE PINTO, I95I, p. 9). Vendo nas manifestações populares da cultura um traço emblemático da desconsideração das "gerações mais velhas diante da falta de educação dos moços" (ROQUETE PINTO, I95 I , p. 9), ela contrapunha o "popular" ao "clássico", como modelos de erro e correção formativa na educação das meninas, respectivamente, já que era impossível essas crianças e adolescentes terem o gosto de "entoar no coro de uma cantata de Bach" (ROQUETE PINTO, 1951 , p. 9). Dito de outra forma, daquele modo seria impossível elas se comportarem "corretamente". Ela notava a adequação do "método bandeirante" para ajudar a reverter a "situação de crise na sociedade brasileira", dizendo ser "ele o mais indicado para solucionar o problema." (ROQUETTE PINTO, I95।, p. 9).

Vianna (1937b, p. 225) reconhecia na mulher brasileira um ímpeto para acompanhar uma sociedade que "ia para adiante", fazendo as meninas assumirem a "luta pela vida". Ela lembra que isso acontecia "sem alarde" e não acarretava, ou, ao menos, não deveria estimular, no entanto, "enthusiasmos suffragistas". Afinal, era "A mulher brasileira, naturalmente dócil e apegada ao lar [...]" (VIANNA, 1937b, p. 225).

Mesmo sem perder a "natural docilidade" e o "apego ao lar", avaliava-se que a mulher havia deixado de ser "parasita", trabalhando, muito, fora de casa, e isso levava as moças brasileiras a abrirem mão dos confortos do lar ou da cidade, para fazer longas caminhadas, acampar ao relento e montar sua própria barraca. Buscava-se sustentar a decisão de praticar as atividades Bandeirantes com o pressuposto educacional de aproximar as meninas da natureza circundante e da sua própria constituição natural (naturalmente "feminina"). Assim, no lugar da apreensão ao ver meninas fazendo atividades de meninos, construía-se a possibilidade de elas "encontrar nesse contato direto com a Natureza, tudo quanto esta mestra admirável pode nos dar de revigorante para o caráter, fortalecedor para o corpo." (FEDERAÇÃO DAS BANDEIRANTES NO BRASIL, 1947, p. 6). 
A necessidade do trabalho e de esforços para além do "cuidado do lar, do marido, e a educação dos filhos" deveria, no entanto, ser uma prática apenas para aquelas que o necessitassem economicamente. As que não precisassem, já teriam nos trabalhos da casa, do casamento e dos filhos ocupações suficientes (VIANNA, 1937b, p. 226). Não se negligenciava a ampliação da esfera de ação profissional e social da mulher, mas assumia-se o espaço privado como o mais adequado ou como o alvo de toda "sua actividade". A mulher que trabalhava fora de casa continuava (ou deveria continuar) a ser "esposa, mãe extremosa e irmã dedicada." A vida "fora de casa" era guiada, no final das contas, pelo retorno a ela: "Ao voltar do trabalho, não vae, como os homens, perder a noite, em cafés e clubs nocturnos. Continua, ainda, a ser mulher do lar." (VIANNA, 1937b, p. 225).

O Bandeirantismo era visto como formador de características volitivas e patrióticas por meio do fortalecimento corporal. A "mulher perfeita", plena de "nobres aptidões", "útil a si mesma e a coletividade", era moldada por meio de uma grande valorização das atividades do corpo, tais como "trabalhos uteis, excursões, jogos e exercícios". A "perfeição", retratada com adjetivos tão enaltecedores, materializar-se-ia na mulher habilitada "para as ocupações domesticas e para ter confiança nela mesma." (VITÓRIA, 1934, p. 36). A esses momentos diretamente ligados ao "chão da casa", associavam-se descrições das virtudes dessa "perfeita mulher": "É o Bandeirantismo o veiculo precioso que conduz as jovens para a perfeição em todos os misteres da vida, Incute, nas moças, o amor do bem, da lealdade, da singeleza, para serem o anjo tutelar da família, uma luz viva que ilumine e aqueça." (VITÓRIA, 1934, p. 36).

Em 1949, Com o título de Como os rapazes veem as moças, publica-se um artigo de Guy de Larigaudie, dirigente do escotismo francês, que explicita as plataformas educacionais do Bandeirantismo em termos mundiais e aceitas no Brasil. Em forma de oração, clamava que as "moças, sejam harmoniosas de corpo, sorridentes e vestidas com gosto." Transparência na alma e saúde, eram fundamentais. Ele também pedia para que meninas fossem "simples", "maternais, sem dissimulação nem coqueteria." Por fim, exortava que "rapazes e moças, nós sejamos, uns para com os outros, uma fonte não de faltas mas de enriquecimento." (LARIGAUDIE, 1949, p. 31).

Todas essas indicações comportamentais partem e chegam ao corpo feminino. Na mesma direção, Fernandes (1927) destaca que a finalidade do movimento Bandeirante seria o desenvolvimento do caráter por meio de atividades que cultivassem a autoconfiança. Além disso, via como relevante o fomento de sentimentos voltados ao bem público, sustentadas pelo altruísmo. Por fim, estava a promoção do "desenvolvimento physico, de tornal-as aptas a serem boas donas de casa e boas educadoras" (FERNANDES, 1927.). Ela complementa, relacionando o desenvolvimento físico com uma nação também mais forte: 
Começando por ser, ella própria, no physico e no moral, um bello especimen de sua raça, um especimen sadios e forte, e educando mais tarde neste sentido, os que the forem confiados, serve ao seu paiz inspirada pelo mais bello patriotismo, pois trabalha dia a dia na obra de sua construcção e de sua grandeza, formando verdadeiros brasileiros, homens de bem, cidadãos uteis á Patria! (FERNANDES, 1927).

Em um documento publicado pela Federação das Bandeirantes no Brasil ( 192 I), também lemos que o desenvolvimento físico sustentaria o cultivo de atitudes e sentimentos relacionados ao papel da mulher na sociedade. Fica estabelecido que às jovens seriam ensinados "trabalhos uteis a elas mesmas", não deixando de complementar que esses trabalhos eram, "principalmente occupações domesticas." (FEDERAÇÃO DAS BANDEIRANTES NO BRASIL, I92। , p. 9). A organização do ensino e das demais atividades a serem feitas pelas garotas baseava-se nas atividades do corpo, conforme se lê sobre o "méthodo": "É o desenvolvimento da iniciativa feminina, ensinando ás moças recreativamente, por meio de jogos e exercicios physicos, a confiar em si mesmas e a formar o seu caracter." (FEDERAÇÃO DAS BANDEIRANTES NO BRASIL, 1921 , p. 9).

Em 1947, a Federação das Bandeirantes no Brasil publica outro documento em que podemos ler que escotismo e Bandeirantismo difeririam apenas em "detalhes" (FEDERAÇÃO DAS BANDEIRANTES NO BRASIL, 1947, p. 4). No que diz respeito às semelhanças, é sublinhado o aprendizado que ocorre "na prática", "na ação". A característica prática dos aprendizados no interior do Bandeirantismo também é enfatizada. $\bigcirc$ corpo seria "mobilizado" para a transmissão de bons hábitos de higiene e da saúde: "A saúde física e a higiene são especialmente cuidadas pelo máximo de vida ao ar livre. Daí as excursões e acampamentos, onde se fazem esportes, exercícios físicos e são incutidas, pela prática, as mais necessárias regras de higiene." (FEDERAÇÃO DAS BANDEIRANTES NO BRASIL, 1947, p. 6).

A missão formativa do Bandeirantismo era sublinhada como um "programa de educação" e não apenas "instrução". (FEDERAÇÃO DAS BANDEIRANTES NO BRASIL, 1947, p. 44). Não se tratava, simplesmente, de "receber de outrem seus conhecimentos", mas sim de terem desenvolvidos o "espírito de comunidade", o caráter e a higiene. Era isso o que tornava "o Bandeirantismo imprescindível à formação da mulher Brasileira” (ROQUETTE PINTO, 195 lb, p. 44). A ênfase na formação do caráter e da saúde no interior das atividades Bandeirantes era endossada por Milliet (1945), ao defender que "O ideal das Bandeirantes é a educação completa: cultivar a saúde, ilustrar o espírito[...]" (MILLIET, I945, p. 27).

Apesar da importância dos resultados formativos do Bandeirantismo e sua ênfase na educação corporal, os representantes do movimento lamentavam que, no Brasil, a estrutura social e os comportamentos arraigados em relação às mulheres, atrapalhavam sua expansão: 
Infelizmente o nosso espírito de família ainda é muito restrito, muito fechado. Não compreende não permite o trabalho social da mulher fora do lar. Não aceita ${ }^{9}$ quando a sua necessidade de dedicação se expande em benefício de outros que lhe não estejam ligados diretamente pelos laços de parentesco. Mas esse sistema de compreender a família nem por isso tem impedido que esta seja solapada pelas forças dissolventes que se agitam hoje no mundo e que conseguem atingir os lares exatamente pela incapacidade da mulher, quando não preparada a fazer face às situações em que a coloca a vida moderna (FEDERAÇÃO DAS BANDEIRANTES NO BRASIL, 1947, p. 9).

Essa constatação era comprovada pelo número de Bandeirantes então existentes (avaliado como pequeno se comparado a outros países), mesmo sendo o escotismo brasileiro um dos mais antigos em todo o mundo (FEDERAÇÃO DAS BANDEIRANTES NO BRASIL, 1947, p. 9). Isso seria intrigante, pois um "país para quem o bandeirantismo seria uma explendida solução para o problema educativo, é exatamente o Brasil (FEDERAÇÃO DAS BANDEIRANTES NO BRASIL, 1947 , p. 10). Interessante notar que as atividades do corpo e a sua capacidade formativa para as mulheres que integravam o Bandeirantismo, mesmo que fomentadoras de representações sobre "novos" e "velhos" fins educacionais para as meninas, também eram vistas como ainda não suficientemente valorizadas pelo "determinado espírito de família $[. .$.$] restrito, muito fechado" preponderante no país.$

\section{CONSIDERAÇÕES FINAIS}

As dificuldades do relacionamento entre meninos e meninas giravam em torno do aspecto institucional e moral do movimento escoteiro. $\bigcirc$ ponto pacífico desse debate era a relevância das atividades físicas para ambos: para os meninos por desenvolverem sua virilidade; para as meninas por prepará-las "the rigors of motherhood and mentally for the partnership of marriage." (PROCTOR, 2002, p. 20). Proctor (2002, p. 22) vai além: "[...] girls would be taught "feminine" virtues, as boys were being taught 'masculine' ones."

Como permitir a experiência de atividades corporais baseadas na aventura e no fortalecimento do corpo, mas evitando que as meninas se tornassem demasiadamente masculinas? Como gerenciar essas atividades, sem fazer com que os meninos deixassem de enxergá-las como apanágios da tão cultuada virilidade masculina? A importância desse debate deu-se não apenas na formação de comportamentos para determinadas expectativas sociais já existentes, mas, "simultaneously participating

9. Lya Roquette Pinto ( 195 I, p. 9) defendia o Bandeirantismo como espaço adequado para que as "ilustres senhoras atacadas pelo sentimento nítido da necessidade de 'fazer alguma coisa' pelo progresso de sua terra", de fato, agissem para além do pouco eficiente papel de "intermitentes patronesses de chás de caridade." 
in the contesting and reshaping of gender roles." (PROCTOR, 2002, p. 26). Essa tensão justifica-se, pois o que estava em jogo eram as possibilidades de rompimentos (vistas no ímpeto das garotas que ansiavam por atividades até então feitas por garotos) e de continuidades em relação aos "antigos" e aos "novos" papéis (vistas na pedagogização desse ímpeto para o reestabelecimento de valores assumidos como enfraquecidos na vida moderna).

Por fim, a ideia de "paradoxo da educação corporal escoteira e bandeirante" foi relevante para chegarmos ao termo desta análise, indicando que o corpo foi o locus de lutas das meninas na primeira metade do século $X X$, pela prática de atividades e pela vivência de situações sociais, até então, restritas aos meninos. A força dessa reivindicação mudou os rumos previamente estabelecidos para o escotismo, uma vez que seus idealizadores mostraram a capacidade de instrumentalizar essas exigências, criando o guiding a partir do scouting para reforçar papéis sociais tradicionais para meninas e meninos. Com isso, Baden-Powell, Juliette Low, assim como os divulgadores do escotismo no Brasil, evidenciam que, como em outros contextos, o "corpo da mulher ao mesmo tempo que é seu não lhe pertence" (GOELLNER, 2003, p. 144). As dissensões sobre essa "posse" mostraram-se pontos nodais para pensarmos as questões educacionais encetadas pelas práticas corporais.

Representations on Female Body and Education of Women by Expansion of Scouting/Guiding During the First Decades of the Twentieth Century

ABSTRACT: The objective of this paper is to analyze the representations on body, education and women within the expansion of Scout movement, which occurred in the early decades of the twentieth century. We studied the work of specialists in the history of education, writings of the founders of the movement in England and in the United States and published articles on Brazilian Guiding. We conclude that the bodily activities practiced within Scouting and Guiding were territories for debate between maintaining and changing social roles assigned to girls and boys.

KEYWORDS: Body; Scouting; Guiding; History of Education.

\section{Representaciones sobre el cuerpo y la educación de las mujeres en la expansión del movimiento scout/guidismo en las primeras décadas del siglo $X X$}

RESUMEN: El objetivo de este trabajo es analizar las representaciones del cuerpo y la educación de la mujer en el interior de la expansión del movimiento Scout, que se produjo en las primeras décadas del siglo XX. Se estudió el trabajo de especialistas en la historia de la educación, escritos de los fundadores del movimiento en Inglaterra y en Estados Unidos y los 
artículos sobre el brasileño Bandeirantismo. Llegamos a la conclusión de que la actividad física y la educación corporal practicada en escultismo y guidismo fueran espacios de tensión entre el mantenimiento y el cambio de los roles sociales asignados a niñas y niños. PALABRAS CLAVE: Cuerpo; boys scouts; guidismo; historia de la educación.

\section{REFERÊNCIAS}

BADEN-POWELL, R. Scouting for boys. London: H. Cox, 1908.

BADEN-POWELL, R. Rovering to success: a book o life-sport for young men. London: J. Jenkis, 1922.

BADEN-POWELL, R. Lessons from the varsity of life. London: Pearson, 1933.

BLOWER, B. D. História do escotismo brasileiro: os primórdios do escotismo no Brasil. Rio de Janeiro: Centro Cultural do Movimento Escoteiro, 1994. v. I.

CAIRE, R. A mulher militar: das origens aos nossos dias. Rio de Janeiro: Biblioteca do Exército, 2002.

CHARTIER, R. A história cultural: entre práticas e representações. Rio de Janeiro: Bertrand Brasil, 2002.

FEDERAÇÃO DAS BANDEIRANTES NO BRASIL. Livro de regras e organização. Rio de Janeiro: Papelaria Americana, 1921.

FEDERAÇÃO DAS BANDEIRANTES NO BRASIL. O bandeirantismo: finalidade, método e sua aplicação no Brasil. Rio de Janeiro: Imprensa Nacional, 1947.

FERNANDES, E. O que são as bandeirantes e como começaram. Alerta!, Rio de Janeiro, n. 4. dez. 1927.

GOELLNER, S. V. Bela, maternal e feminina: imagens da mulher na revista Educação Physica. ljuí: Ed. da Unijuí, 2003.

JEAL, T. Baden-Powell: founder of the boy scouts. Yale: Nota Bene, 200 I.

LARIGAUDIE, G. de. Como os rapazes veem moças. Bandeirantes, n. 208, p. 3 I , abr. 1949.

LOW, J. G.; BADEN-POWELL, R.; BADEN-POWELL, A. M. How girls can help their country. 1917. Ebook. Disponível em: www. gutemberg.org.br.

MACLEOD, D. Building character in the american boy: the boy scouts, YMCA, and their forerunners, 1870-1920. London: University of Wisconsin, 1983.

MILLIET, D. A. O Bandeirantismo. Educação Physica, n. 87, p. 27/40, jul./ago. 1945. 
PROCTOR, T. "On my honour": guides and scouts in interwar britain. Philadelphia: Transactions of the American Philosophical Society, 2002. v. 92. pt. 2.

PROCTOR, T. Scouting for girls: a century of girl guides and girl scouts. Santa Barbara: ABC Clio, 2009.

ROQUETTE PINTO, L. A oportunidade do Bandeirantismo para o Brasil. Bandeirantes, n. 224, p. 9-10, mar. 1951.

ROQUETTE PINTO, L. A oportunidade do Bandeirantismo para o Brasil (continuação). Bandeirantes, n. 225/226, p. 44-45, abr./maio 1951.

ROSENTHAL, M. The character factory: Baden-Powell and the origins of the boy scout movement. London: Collins, 1986.

SCHARADGRODSKY, P. A. El scautismo en la educación física bonaerense: Argentina o acerca del buen encauzamiento varonil (1914-1916). Revista Brasileira de Ciências do Esporte, Campinas, v. 29, n. 3, p. I55-177, maio 2008. Disponível em: http://www.rbceonline.org. br/revista/index.php/RBCE/article/view/216/219. Acesso em: 2 jan. 2013.

VIANNA, M. S. B. Leis sobre o trabalho feminino. Bandeirantes, n. II0, p. 190-191, ago. 1937 .

VIANNA, M. S. B. Leis sobre o trabalho feminino (continuação). Bandeirantes, n. | | | / | 2, p. 225-228, set./out. 1937b.

VITÓRIA E O MOVIMENTO BANDEIRANTE. Revista de Educação, Vitória, v. I, n. 2, p. 36, maio 1934.

Recebido em: 18 dez. 2012 Aprovado em: 28 jul. 2013

Endereço para correspondência:

Carlos Herold Jr. Rua Marechal Deodoro 530, apto I 43. CEP 87030-020 Maringá-PR. 